\title{
CIENTIFICISMO, MODO FANTÁSTICO E REPRESENTAÇÃO DO GÊNERO FEMININO EM “O CAPITÃO MENDONÇA”, DE MACHADO DE ASSIS
}

\author{
SCIENTISM, FANTASTIC MODE AND REPRESENTATION OF \\ FEMALE GENDER IN “O CAPITÃO MENDONÇA”, BY MACHADO \\ DE ASSIS
}

\author{
Greicy Pinto BELLIN* \\ James Remington KRAUSE ${ }^{* *}$
}

\begin{abstract}
Resumo: O presente artigo realiza uma análise do conto "O capitão Mendonça", de Machado de Assis, procurando percebê-lo como uma crítica em relação ao cientificismo emergente no século XIX, às representações do gênero feminino na época e à apropriação do modo fantástico europeu na literatura brasileira, mais especificamente "O homem da areia", de E. T. A. Hoffmann. Como embasamento teórico, lançaremos mão das reflexões de: Joan Scott e Teresa de Lauretis, a fim de refletir sobre a questão de gênero e sobre as tecnologias envolvidas em sua construção e representação, considerando a existência de certas configurações do gênero feminino que refletiam as condições sociais da mulher na sociedade do século XIX; Jaison Luís Crestani, no que se refere às questões editoriais envolvendo os periódicos que circulavam na época de Machado, entre eles o Jornal das Famílias, no qual "O capitão Mendonça" foi publicado em formato de folhetim; Linda Hutcheon, no que se refere à utilização da paródia para o exercício da crítica em relação às questões de gênero e influências advindas da literatura europeia, com o objetivo de analisar e identificar a postura de Machado em relação a essas questões; e Rosemary Jackson, David Roas, Irene Bessière e Remo Ceserani no que se refere às apropriações do modo fantástico.
\end{abstract}

Palavras-chave: Cientificismo. Modo fantástico. Gênero. Paródia. Periódicos.

\begin{abstract}
This paper analyzes the short-story "O capitão Mendonça”, by Machado de Assis, seeking to perceive it as a threefold critique: i) of the emergence of nineteenth-century scientism in Brazil, ii) of female gender representations, and iii) of the appropriation of the fantastic mode of European literature in Brazilian literature, specifically of "The Sandman", by E. T. A. Hoffmann. It draws on Joan Scott's and Teresa de Lauretis's works, in order to reflect upon the technologies involved in gender construction and representation, considering the existence of certain configurations of the female gender which reflected women's social conditions in the $19^{\text {th }}$ century society; on Jaison Luís Crestani, in relation to the editorial matters concerning the periodicals which circulated in Assis's time, among them Jornal das Famílias, in which "O capitão Mendonça" was published in the format of a serialized novel; on Linda Hutcheon, in relation to the use of parody for exercising critique when it comes to gender matters and influences coming from European literature, with the aim of analyzing and identifying Assis's attitude in relation to these matters; and on Rosemary Jackson, David Roas, Irene Bessière and Remo Ceserani regarding the appropriations of the fantastic mode.
\end{abstract}

Keywords: Scientism. Fantastic mode. Gender. Parody. Periodicals.

\footnotetext{
* Doutora em Estudos Literários pela Universidade Federal do Paraná (UFPR) e pós-doutora na mesma área pela Universidade Estadual de Campinas (UNICAMP). Professora titular de Teoria Literária e Literatura Inglesa/Norteamericana do Programa de Pós-Graduação em Teoria Literária do Centro Universitário Campos de Andrade (UNIANDRADE).E-mail: greicy.bellin@uniandrade.edu.br. ORCID: https://orcid.org/0000-0003-3787-7722

** Doutor pela Vanderbilt University, atuou como professor de Língua Portuguesa e Literaturas Lusófonas em Brigham Young University (Provo, Utah, EUA). E-mail: jimjiminy @ gmail.com. ORCID: https://orcid.org/00000001-8129-5389
} 
Joaquim Maria Machado de Assis (1839-1908) realizou algumas incursões pelo modo fantástico, principalmente em seus contos. Inspirado pelas obras de E. T. A. Hoffmann, Edgar Allan Poe, Théophile Gautier e Guy de Maupassant, o escritor brasileiro incorporou aspectos da ficção fantástica, sejam eles alegóricos, sobrenaturais ou psicológicos, em pelo menos 30 de seus 200 contos ao longo da carreira.

Pelo menos uma dúzia destes contos aparece em antologias, tanto em português quanto em tradução estrangeira, mas o restante permanece às margens dos estudos machadianos, situação que vem mudando nos dias de hoje. No espaço de duas décadas, cresceu o interesse acadêmico pela questão do fantástico em Machado de Assis, ainda que este não seja um dos tópicos mais explorados por sua fortuna crítica. Vários estudos produzidos nos últimos anos comprovam este interesse, entre eles a dissertação de mestrado de Ricardo Gomes da Silva, intitulada "Um esqueleto de Machado de Assis e outros contos parodicamente fantásticos", defendida na Universidade Estadual de Londrina no ano de 2012, bem como os artigos “"O capitão Mendonça': um conto fantástico de Machado de Assis”, de autoria de Sandra Maria Steilein, publicado em 1992, "Fazendo apetite para o chá: narrativa fantástica e identidade nacional em "Um esqueleto", de Machado de Assis", de Greicy Pinto Bellin, publicado em 2016, e "The femme fragile and the femme fatale in the fantastic fiction of Machado de Assis", de Jordan Jones e James Remington Krause, publicado em 2015.

Para além da questão do fantástico, Machado apontou com frequência para as limitações na aplicação do pensamento científico e das técnicas científicas na compreensão da condição humana mesmo antes do surgimento das teorias de Charles Darwin, Auguste Comte e Herbert Spencer e seu enraizamento na sociedade brasileira nas duas últimas décadas do século XIX. Pode-se afirmar, entretanto, que o escritor manteve uma distância cética em relação a estas teorias, conforme citação de José Raimundo Maia Neto:

Machado não compartilhava do entusiasmo e do otimismo de seus contemporâneos,
que viam nas "novas ideias" a posterior derrubada da metafísica e da monarquia, bem
como o estabelecimento da ciência e do republicanismo. Por outro lado, o escritor não
se manteve ileso ao prevalente ceticismo religioso de sua época (NETO, 2007, p.26).

Talvez a mais célebre crítica de Machado ao cientificismo apareça materializada no Humanitismo de Quincas Borba, personagem que aparece em romance homônimo e também em Memórias póstumas de Brás Cubas. Críticas mais diretas do escritor em relação à ciência empírica enquanto visão de mundo autoritária em sua época podem ser vistas em suas 
representações do cientista, figura que aparece em, pelo menos, oito contos machadianos, três deles escritos no modo fantástico: "O capitão Mendonça” (1870), “O alienista” (1881) e "A causa secreta" (1885). Os outros cinco contos são: “O segredo do bonzo" (1882), “A sereníssima república” (1882), "O lapso" (1883), "Conto alexandrino" (1883) e "Ex cathedra" (1884). Muitos estudiosos analisam estes dois últimos contos como uma crítica direta ao positivismo, ao passo que "O capitão Mendonça" veicularia, a partir do modo fantástico, uma crítica à emergência do método científico no Brasil, crítica esta atrelada a questões editoriais, literárias e de gênero, conforme analisaremos neste artigo.

"O capitão Mendonça" é o primeiro conto de Machado de Assis a trazer a representação de um cientista. Na visão de Isabel Cristina Hentz, "Machado construía homens de ciência que, a princípio, parecem seres magnânimos, mas que, ao longo das narrativas, se mostram mesquinhos, sem noção de limites e, muitas vezes, loucos” (HENTZ, 2011, p.2), o que será observado no conto escolhido para análise neste artigo, o qual foi compilado em duas coletâneas de Raimundo Magalhães Júnior: Contos recolhidos (1956) e Contos fantásticos de Machado de Assis (1975). Sua primeira publicação, contudo, se deu no Jornal das Famílias, periódico que circulou entre os anos de 1863 e 1878, direcionado a um público leitor majoritariamente formado por mulheres da elite fluminense e que tinha como principal editor o francês Baptiste Louis Garnier (1823-1893). Compreender a natureza do público leitor da ficção fantástica machadiana é de fundamental importância para o entendimento das configurações de gênero presentes na narrativa, bem como da crítica que será tecida ao aparecimento do cientificismo no Brasil do século XIX. Levaremos em consideração, nesta análise, os conceitos de gênero e de tecnologia de gênero explicitados por Joan Scott e Teresa de Lauretis, bem como o conceito de paródia de Linda Hutcheon e conceito de fantástico explicitado por Todorov, além discussões atuais acerca do modo fantástico, empreendidas por Irene Bèssiere, David Roas, Filipe Furtado, Rosemary Jackson e Remo Ceserani, reflexões estas de grande relevância para a compreensão da narrativa.

\section{Gênero, tecnologia de gênero e Jornal das famílias: algumas considerações}

Em “O capitão Mendonça”, Machado de Assis lança mão do modo fantástico para apresentar uma visão crítica acerca do cientificismo e da incorporação do modelo fantástico europeu, reforçando e subvertendo, ao mesmo tempo, configurações relativas ao gênero feminino. Apresentaremos algumas considerações sobre o conceito de gênero que nos auxiliarão a compreender a representação da figura feminina presente no conto. 
Este conceito surge em um momento de arrefecimento da luta radical que caracterizou a primeira fase do feminismo, marcada por uma vertente revisionista, que pretendia denunciar a opressão feminina por meio de uma análise das representações de mulheres em obras fundamentais da literatura ocidental. Neste sentido, a criação era concebida como algo essencialmente masculino, ao passo que a mulher seria sempre um objeto de representação. Tais aspectos são explorados na reflexão de Sandra Gilbert e Susan Gubar, que, com seu livro The Madwoman in the Attic, procuraram realizar uma arqueologia das representações femininas sem, naquele momento (o livro foi escrito em 1979), recorrer ao conceito de gênero, que ganharia mais espaço nos círculos intelectuais a partir da década de 1990.

Joan Scott foi uma das primeiras historiadoras a usar o gênero como categoria de análise, definindo-o como "toda e qualquer construção social, simbólica, culturalmente relativa, da masculinidade e da feminilidade. Ele define-se em oposição ao sexo, que se refere à identidade biológica dos indivíduos" (SCOTT, 1990, p.5). Teresa de Lauretis, por sua vez, aponta para a existência dos sistemas sexo-gênero, baseados em uma associação entre estas duas instâncias dentro de um contexto sociocultural definido: "as concepções culturais de masculino e feminino como duas categorias complementares formam, dentro de cada cultura, um sistema de gênero, um sistema simbólico ou um sistema de significações que relaciona o sexo a conteúdos culturais de acordo com valores e hierarquias sociais” (LAURETIS, 1994, p. 211). A literatura seria um dos sistemas de significação referenciados pela autora, na qual forma e conteúdo se associam para veicular as representações de gênero presentes na sociedade.

Outra conquista fundamental da reflexão de Lauretis diz respeito à análise do gênero como representação, e desta representação como sua construção, o que encontra respaldo no artigo intitulado "A tecnologia do gênero" (1994). Em tal artigo, a autora propõe que a representação do gênero é produto de uma construção levada a cabo por tecnologias variadas, partindo de um conceito desenvolvido por Michel Foucault, que define "tecnologia" como "um conjunto de técnicas para maximizar a vida", criada e desenvolvida "pela burguesia a partir do final do século XVIII para assegurar a sobrevivência da classe e a continuação da hegemonia" (LAURETIS, 1994, p.220). O cinema é referido por Lauretis como tecnologia de construção de gênero na sociedade contemporânea, construção esta permeada por ideologia, a qual, na visão de Althusser, "representa não o sistema de relações reais que governam a existência de indivíduos, e sim a relação imaginária daqueles indivíduos com as relações reais em que vivem" (LAURETIS, 1994, p.212). 
No caso de Machado de Assis, as tecnologias utilizadas para a construção do gênero eram, além dos periódicos dirigidos ao público feminino, o folhetim, que auxiliava na perpetuação de determinadas representações de gênero que reforçavam a mentalidade patriarcal, e que exerciam uma função didática perante um público leitor submetido a determinados padrões de comportamento característicos do que Eric Hobsbawm (2012) chamaria de "o anjo do lar". Trata-se de expressão utilizada para se referir às construções que colocavam a mulher como ser doce, assexuado e submisso, alguém que deveria zelar pelo bem-estar de sua família, representação esta frequente na literatura oitocentista. Estabelece-se, portanto, uma nítida associação entre gênero, tecnologia de gênero e imprensa periódica, de forma que uma instância seria dificilmente compreendida sem a outra.

De acordo com Jaison Luís Crestani, em Machado de Assis no Jornal das Famílias (2009), a introdução da mídia de massa no Brasil apresentou uma relação dialética. De um lado, havia a possibilidade de um maior acesso à informação, o que facilitou a disseminação de ideais democráticos, acelerando o desenvolvimento cultural. De outro, artistas e escritores cederam às pressões do mercado a fim de produzir formas mais diluídas e triviais de expressão cultural para consumo em massa e visando maior lucratividade. Os jornais brasileiros experimentaram grande sucesso comercial a despeito do alto índice de analfabetismo ao seguir a tendência do romance folhetim, bem-sucedido em Londres e Paris. Muitos escritores brasileiros do período romântico, entre eles Joaquim Manuel de Macedo e José de Alencar, começaram a colaborar em jornais no formato folhetim antes de publicar suas narrativas no gênero romance e/ou em coletâneas de contos, um gênero relativamente novo praticado naquela época.

Na visão de Crestani (2009), enquanto algumas políticas de publicação pareciam triviais, como aumentar o tamanho das histórias para que elas fossem contadas em vários fascículos do Jornal, outras políticas possuíam implicações mais significativas. Uma dessas políticas se configurava no policiamento ideológico estabelecido a partir das representações femininas e masculinas nas narrativas, as quais possuíam, conforme já explicitado, um tom moralizante que não ofenderia os pais, maridos e/ou irmãos que pagavam pela assinatura do Jornal das Famílias, o que o transformava em um verdadeiro baluarte da moral e dos bons costumes. Esta situação, além de apontar para uma possível subalternidade da mulher, fazia com que Machado de Assis, colaborador assíduo do periódico, andasse no "fio da navalha" (CRESTANI, 2006, p. 152). Esta postura se caracterizava pela oscilação entre se adequar ao perfil exigido pelos editores e, ao mesmo tempo, exercer uma crítica em relação a questões presentes no contexto brasileiro da época, entre elas a questão do adultério. Exemplar neste sentido é o conto "Confissões de uma 
viúva moça”, alvo de polêmica no Correio Mercantil, na qual um leitor ranzinza chamado Caturra comenta a respeito do caráter imoral da narrativa:

\begin{abstract}
Jornal das Famílias
[...] No último número deste jornal, que se diz das famílias, e cujo programa já vai se afastando sofrivelmente, enceta-se a publicação de um romancito sob o título Confissões de uma viúva moça. Pela amostra do pano desde já se pode conjeturar de que magnificência será o vestido que trata-se de expor à atenção das jovens, que têm um dia de serem esposas e mães de família, isto é, daquelas que bem deverão compreender qual a verdadeira missão dos filhos, e os legítimos gozos ocorrentes que suavizam os frequentes cuidados de respeitável mãe de família. Para os pais de família, pés de boi, os que têm a esquisitice de verem a realidade deste mundo pelo prisma rococó escrevemos estas ligeiras linhas, pedindo-lhes que façam companhia às suas filhas na apreciação de tão edificantes escritos, tão harmoniosos como os esplendores deste século reformista (O CATURRA, apud MASSA, 1965, p. 210).
\end{abstract}

O próprio Machado respondeu às acusações, em uma querela interpretada por alguns críticos machadianos como um golpe publicitário por parte do editor Garnier, que estaria preocupado com a queda nas vendas resultante da eclosão da Guerra do Paraguai, em 1865 (o conto foi publicado no formato de folhetim no mesmo ano). Este episódio evidencia a extensão da questão ideológica que permeava as representações de gênero e a circulação da literatura no contexto oitocentista, bem como a questão da importação francesa, considerando que o periódico era editado por um francês e diagramado em Paris para ser publicado no Brasil. No conto "Confissões de uma viúva moça", Eugênia, a protagonista da narrativa, comete adultério por influência de leituras de romances franceses, situação que se repete em outros romances famosos da literatura ocidental, entre eles Madame Bovary, de Gustave Flaubert, e O primo Basílio, de Eça de Queiróz.

"O capitão Mendonça”, por outro lado, desenvolve temática diversa, tendo sido publicado nas edições de abril e maio do Jornal das Famílias. Sua leitura nos remete a "O homem da areia", de E. T. A. Hoffmann, publicado em 1816, o que daria margem para uma análise intertextual, tema que James Remington Krause explora em “Enucleated Eyes: 'Sem olhos' and 'O capitão Mendonça' by Machado de Assis" (2009). As cenas inquietantes de horror da narrativa machadiana, ambientadas no interior de uma estrutura pseudocientífica, parecem, a princípio, não corresponder aos objetivos dos editores e leitores do periódico, mas a análise do conto mostrará as razões pelas quais ele foi aceito e publicado neste mesmo periódico, considerando seu nível de conservadorismo.

Outros contos considerados fantásticos foram também publicados no periódico de Garnier, entre eles “Um esqueleto”, em 1875, e "Sem olhos”, em 1876. As duas narrativas lidam 
com a questão do adultério, recorrendo ao modo fantástico para exercer críticas em relação à apropriação da ciência no contexto brasileiro, como no caso do primeiro, e em relação à moralidade que envolvia a traição feminina, caso de ambos. Os dois contos trazem a representação da figura feminina como dócil e submissa, um verdadeiro objeto da adoração e da obsessão masculinas, o que se torna claro em "Um esqueleto" na bizarra atitude do Dr. Belém ao "convidar" o esqueleto da falecida esposa para jantar com a segunda. Um aspecto que aproxima "O capitão Mendonça" destes dois contos é o que Raimundo Magalhães Júnior chamou de "rasteira machadiana", baseada na desmistificação do horror causado pela narrativa fantástica, o que encontra respaldo na seguinte fala do narrador Alberto em "Um esqueleto" ao encerrar a narrativa sobre o Dr. Belém: "Mas o Dr. Belém não existiu nunca, eu quis apenas fazer apetite para tomar chá” (ASSIS, 2008, p.1371). Considerações sobre o modo fantástico e sobre o conceito de paródia se fazem necessárias para compreender as narrativas de Machado, em especial "O capitão Mendonça", conforme veremos a seguir.

\section{O modo fantástico e a paródia: uma breve reflexão}

A teoria literária contemporânea apresenta duas tendências principais para a compreensão do fantástico: o fantástico enquanto gênero, e o fantástico enquanto modo. Tzvetan Todorov é o teórico balizador da primeira vertente, o que encontra respaldo no lançamento, em 1973, do famoso Introdução à literatura fantástica, em que, na visão de Marisa Martins Gama-Khalil, o autor organizou "os estudos anteriores, reunindo-os, discutindo-os e, a partir deles, imprimido uma perspectiva teórica que agrupou formas similares de trabalho com o sobrenatural e apartou essas formas de outras, com características dissonantes" (GAMA-KHALIL, 2013, p.19).

Para Todorov, o fantástico acontece em função de uma incerteza, ao passo que o estranho teria uma explicação racional e o maravilhoso seria caracterizado por elementos pertinentes àquele mundo ficcional e não suscitaria hesitação. O fantástico se localizaria, portanto, entre o estranho e o maravilhoso, sendo que a hesitação seria a definidora das sensações inquietantes experimentadas pelo leitor. As definições apresentadas por Todorov acabaram por circunscrever o fantástico nos moldes de um gênero com convenções rígidas para a sua configuração, o que acabou por originar questionamentos como os apresentados por Filipe Furtado, um dos estudiosos responsáveis pelo deslocamento da noção de hesitação: 
função do narratário terá de subordinar-se, servindo-a, à ambiguidade fundamental que o texto deve veicular (FURTADO, 1980, p.40-1).

David Roas, da mesma forma, aborda as fragilidades da teoria todoroviana ao afirmar que a hesitação não seria, necessariamente, o traço definidor do fantástico, que se definiria muito mais em função da ambiguidade gerada durante o processo de leitura do que da hesitação em si:

\begin{abstract}
Concluindo, o fantástico é, para Todorov, aquela categoria evanescente que se definiria pela percepção ambígua que o leitor implícito tem dos acontecimentos relatados e que compartilha com o narrador ou com um dos personagens. Na minha opinião, esta é uma definição muito vaga e, acima de tudo, muito restritiva do fantástico, pois embora seja perfeita para definir narrativas como Outra Volta do Parafuso [...], de Henry James, ficariam fora de tal definição muitas histórias em que não há hesitação possível, uma vez que apenas uma explicação sobrenatural dos fatos pode ser aceita (ROAS, 2001, p. 16-17, tradução nossa) ${ }^{1}$.
\end{abstract}

Tais discussões acabaram por dar origem a uma percepção acerca do fantástico enquanto modo, o qual abarcaria, para Irene Bessière, uma gama de narrativas que lidam com a incerteza. Cabe ressaltar, neste sentido, que, apesar de se opor à concepção de Todorov, a autora não chega a cunhar a noção de modo fantástico, sugerindo caminhos para este entendimento e abrindo perspectivas para os estudiosos que virão a trabalhar com esta ideia:

\begin{abstract}
A história fantástica provoca incerteza, no exame intelectual, porque se utiliza de dados contraditórios recolhidos de acordo com sua própria coerência e complementaridade. Não define uma qualidade atual de objetos ou seres existentes, nem constitui uma categoria ou gênero literário, mas supõe uma lógica narrativa tanto formal quanto temática que, surpreendente ou arbitrária para o leitor, reflete, sob o aparente jogo da invenção puro, as metamorfoses culturais da razão e do imaginário coletivo (BESSIÈRE, 2001, p. 84, tradução nossa)².
\end{abstract}

Para Rosemary Jackson, em Fantasy: literatura y subversión (1986), a fantasia seria a definidora por excelência da literatura fantástica, cujo estudo não poderia ser categorizado em gêneros que, ao fim e ao cabo, limitariam o escopo das análises, conduzindo a leituras pouco

\footnotetext{
${ }^{1}$ No original: "En conclusión, lo fantástico es, para Todorov, esa categoría evanescente que se definiría por la percepción ambigua que el lector implícito tiene de los acontecimientos relatados, y que este comparte con el narrador o con alguno de los personajes. A mi entender, ésta es una definición muy vaga y, sobre todo, muy restrictiva de lo fantástico, puesto que si bien resulta perfecta para definir narraciones como Otra vuelta tuerca [...], de Henry James, quedarían fuera de tal definición muchos relatos en los que no hay vacilación posible, puesto que sólo se puede aceptar una explicación sobrenatural de los hechos."

${ }^{2}$ No original: "El relato fantástico provoca la incertidumbre, en el examen intelectual, porque utiliza datos contradictorios reunidos según una coherencia y una complementariedad propias. No define una cualidad actual de objetos o seres existentes, como tampoco constituye una categoría o un género literario, pero supone una lógica narrativa a la vez formal y temática que, sorprendente o arbitraria para el lector, refleja, bajo el aparente juego de la invención pura, las metamorfosis culturales de la razón y del imaginario colectivo."
} 
abrangentes. Jackson afirma que o modo fantástico se estrutura em dois polos: o maravilhoso e o mimético, opondo-se a Todorov ao não tratar estes dois polos como gêneros distintos e sim “como grandes formas geradoras do modo literário fantástico" (GAMA-KHALIL, 2013, p. 26). Remo Ceserani (2006), assim como Irene Bessière mas com base em Jackson, é outro teórico que percebe o fantástico enquanto modo caracterizado pela poética da incerteza, advertindo para a importância de se perceber e analisar os procedimentos narrativos no corpo da narração, a narração em primeira pessoa, o envolvimento do leitor, entre outros aspectos que contribuiriam para a sua definição. No caso dos contos fantásticos machadianos, tanto os procedimentos narrativos quanto a narração em primeira pessoa são importantes para o enquadramento no modo fantástico, uma vez que possibilitarão a "rasteira machadiana" mencionada por Magalhães Júnior. Esta, ao menos na visão de Todorov, não possibilitaria a percepção dos contos de Machado como fantásticos, daí nossa opção pelo uso do modo fantástico para analisar "O capitão Mendonça".

Outro componente relevante do modo fantástico conforme a reflexão de Remo Ceserani é a paródia, em entrelaçamento definido da seguinte maneira:

Se a ligação entre a temática romântica - vida profunda do eros, frustrações e
sublimaços - e a narrativa fantástica viesse estabelecida e provada, a hesitação
instilada por esse tipo de conto nos leitores não seria mais tanto entre uma explicação
natural e uma sobrenatural dos eventos contados, mas entre uma história superficial
(...) e de uma outra história, mais profunda e significativa, que por todo o tempo foi
indiretamente contada. A presença de elementos de paródia e de discussão
metanarrativa sobre os modos e sobre os códigos da narração parece uma indicação e
uma sugestão da ambiguidade de toda a operação estratégica: a literatura fantástica
finge contar uma história para poder contar outra (CESERANI, 2006, p. 102).

Observam-se claros indícios de paródia de "O homem da areia" no conto machadiano, considerando, principalmente, a forma pela qual Machado irá representar a personagem Augusta. E. T. A. Hoffmann, por sua vez, apresentava ampla aceitação no contexto literário do século XIX, conforme afirmação de Karin Volobuef:

Se o sucesso de Hoffmann foi enorme em vida, após sua morte em 1822, seu nome caiu no esquecimento na Alemanha. Na França, porém, sua aclamação estava apenas começando. A partir de 1828 saía pela editora Randuel a longa fileira de traduções assinada pela Loève-Veimars - um empreendimento que acabou totalizando 20 volumes (VOLOBUEF, 2002, p.1).

A citação da autora remete ao fato, aliás amplamente reconhecido, de que as obras alemãs e inglesas chegavam ao Brasil por meio de traduções francesas, o que levou à popularização do 
fantástico alemão no contexto cultural brasileiro oitocentista, dada a hegemonia da França neste mesmo contexto. Estas informações nos conduzem à interpretação de que Machado, para além da reflexão sobre os papéis de gênero e da crítica ao cientificismo europeu, estaria lançando mão do modo fantástico para tecer uma crítica à incorporação do modelo fantástico europeu na literatura brasileira de sua época. Tal perspectiva poderia ser validada a partir da citação de Ceserani, segundo o qual a "literatura fantástica finge contar uma história para poder contar outra”, o que se daria por meio da paródia e da apropriação irônica de modelos estrangeiros, como acontece em "O capitão Mendonça".

O termo "paródia" é também importante para o desenvolvimento desta análise, em reflexões teóricas que contam com as reconhecidas contribuições de Mikhail Bakhtin e Linda Hutcheon. Para Bakhtin, a paródia carnavaliza o discurso literário, tendo intenção necessariamente ridicularizadora, sinalizando a presença de outras vozes e/ou outros discursos em um texto: "ao discurso parodístico é análogo o emprego irônico e todo o emprego ambíguo do discurso do outro, pois também nesses casos o discurso é empregado para lhe transmitir intenções que lhe são hostis" (BAKHTIN, 1997, p. 195). Hutcheon, por outro lado, não percebe a paródia como obrigatoriamente ridicularizadora, pois a etimologia do termo comporta a ideia de contracanto, isto é, de canto paralelo ao original. Ao fazer paródia, portanto, o (a) escritor (a) pode elogiar e até mesmo, subverter o discurso parodiado, sendo muitas vezes frequente o componente de autorreflexividade, o qual remete ao desenvolvimento de percepções críticas em relação ao texto parodiado. A paródia é, também, elemento recorrente não apenas no texto machadiano em si, mas nas reflexões empreendidas por estudiosos da obra do autor. Seu uso passou a ser investigado com maior profundidade a partir da contribuição teórica de José Guilherme Merquior, que, no artigo intitulado "Gênero e estilo nas Memórias póstumas de Brás Cubas", afirma que a paródia tem a função de dessacralizar e carnavalizar o que chamou de "novela filosófica". Dirce Corte Riedel, por sua vez, afirma que "o texto de Machado é quase sempre baseado na paródia" (RIEDEL, 1979, p. 5), ao passo que Enylton de Sá Rego (1989) afirma que a obra machadiana é marcada pela utilização sistemática da paródia e da mistura de gêneros literários. A associação entre paródia e modo fantástico, já explicitada por Remo Cesarani, justifica sua utilização na análise do modo fantástico machadiano, considerando o potencial criativo que emerge deste uso em sua relação com outros textos, bem como a intenção reflexiva e de subversão em relação a eles. 


\section{“O capitão Mendonça": modo fantástico, crítica ao cientificismo e representação feminina}

“O capitão Mendonça” conta a história de um pai que tenta arranjar o casamento de sua filha com um jovem e respeitável rapaz. Neste sentido, a narrativa reforçaria, de saída, uma mentalidade tradicional associada a certos papéis e expectativas relacionadas ao gênero feminino, adicionando a eles um componente de horror a partir da constatação de que Augusta seria uma criação artificial de seu pai, o próprio capitão Mendonça.

A história se abre com Amaral indo para o teatro assistir a um melodrama a fim de se distrair por conta de um desentendimento com "a dama de meus pensamentos" (ASSIS, 2008, p.970). Durante o primeiro intervalo, o capitão Mendonça, amigo do pai de Amaral, o reconhece por conta de sua semelhança com seu genitor e o convida para jantar em sua casa. É importante ressaltar que o início da ação transcorre no teatro, sendo que o enredo da peça assistida por Amaral prenuncia aspectos que aparecerão no desenrolar da narrativa de Machado:

\footnotetext{
$\mathrm{O}$ ato prometia; começava por um homicídio e acabava por um juramento. Havia uma menina, que não conhecia pai nem mãe, e era arrebatada por um embuçado que eu suspeitei ser a mãe ou o pai da menina. Falava-se vagamente de um marquês incógnito, e aparecia a orelha de um segundo e próximo assassinato na pessoa de uma condessa velha. O ato acabou com muitas palmas (ASSIS, 2008, p. 970-971).
}

A "menina que não conhecia pai nem mãe" pode ser correlacionada com Augusta, que está na mesma condição não pelo fato de ser órfã, mas por ser um produto da ciência. Depois do segundo ato da peça, Amaral e Mendonça se dirigem à casa do capitão, localizada na rua da Guarda Velha e descrita como lúgubre, quase infernal:

O velho bateu três pancadas; daí a alguns segundos rangia a porta nos gonzos e nós entrávamos num corredor escuro e úmido.

— Então não trouxeste luz? perguntou Mendonça a alguém que eu não via.

- Vim com pressa.

- Bem; fecha a porta. Dê cá a mão, sr. Amaral; esta entrada é um pouco esquisita, mas lá em cima estaremos melhor.

Dei-lhe a mão.

— Está trêmula, observou o capitão Mendonça.

Eu tremia, com efeito; pela primeira vez surgiu-me no espírito a suspeita de que o pretendido amigo de meu pai não fosse mais que um ladrão, e aquilo uma ratoeira armada aos néscios.

Mas era tarde para retroceder; qualquer demonstração de medo seria pior. Por isso, respondi alegremente:

- Se lhe parecer que não há de tremer quem entre por um corredor como este, o qual, haja de perdoar, parece o corredor do inferno.

- Quase acertou, disse o capitão, guiando-me pela escada acima.

- Quase?

— Sim; não é o inferno, mas é o purgatório. 
Estremeci ao ouvir estas últimas palavras; todo o meu sangue precipitou-se para o coração, que começou a bater apressado. A singularidade da figura do capitão, a singularidade da casa, tudo se acumulava para encher-me de terror. Felizmente chegamos acima e entramos para uma sala iluminada a gás, e mobiliada como todas as casas deste mundo (ASSIS, 2008, p. 973).

O percurso de ambos os personagens até a entrada da residência remete a dois contos de Edgar Allan Poe: "O barril de Amontillado" (1846) e "A queda da casa de Usher" (1839), os quais, conforme já explicitado no início deste artigo, podem ter tido provável influência sobre Machado na composição de sua narrativa. Ao entrarem na sala de jantar eles encontram Augusta, filha de Mendonça. No mesmo momento, Amaral é seduzido pelo comportamento coquete da moça e por seus perturbadores olhos verdes. A descrição física de Augusta traz uma série de componentes românticos que corroboram a idealização da figura feminina dentro de uma configuração de gênero que a concebe como angelical e submissa:

\begin{abstract}
Augusta levantou para mim dois belíssimos olhos verdes. Depois sorriu e abaixou a cabeça com ar de casquilhice ou de modéstia, porque ambas as coisas podiam ser. Contemplei-a nessa posição; era uma formosa cabeça, perfeitamente modelada, um perfil correto, uma pele fina, cílios longos, e cabelos cor de ouro, áurea coma, como os poetas dizem do sol (ASSIS, 2008, p. 974).
\end{abstract}

Mendonça percebe o flerte entre os dois e pergunta a Amaral se ele gostaria de ver de perto os olhos da moça:

\footnotetext{
Dizendo isto, levantou-se o capitão e aproximou-se de Augusta, que inclinou a cabeça sobre as mãos dele. $\mathrm{O}$ velho fez um pequeno movimento, a moça ergueu a cabeça, o velho apresentou-me nas mãos os dous belos olhos da moça.

Olhei para Augusta. Era horrível. Tinha no lugar dos olhos dous grandes buracos como uma caveira. Desisto de descrever o que senti; não pude dar um grito; fiquei gelado. A cabeça da moça era o que mais hediondo pode criar imaginação humana; imaginem uma caveira viva, falando, sorrindo, fitando em mim os dous buracos vazios, onde pouco antes nadavam os mais belos olhos do mundo. Os buracos pareciam ver-me; a moça contemplava o meu espanto com um sorriso angélico.

Olhei para os olhos que o velho tinha na mão. Aqui foi pior; os dous olhos estavam fitos em mim, pareciam compreender-me tanto quanto os buracos vazios do rosto da moça; separados do rosto, não os abandonara a vida; a retina tinha a mesma luz e os mesmos reflexos. Daquele modo as duas mãos do velho olhavam para mim como se foram um rosto (ASSIS, 2008, p. 976).
}

Horrorizado, Amaral pensa em escapar, sem sucesso. O capitão Mendonça explica que Augusta é sua obra-prima, o resultado de três anos de experimentos alquímicos, um verdadeiro milagre da ciência: 
Augusta é a minha obra-prima. É um produto químico; gastei três anos para dar ao mundo aquele milagre; mas a perseverança vence tudo, e eu sou dotado de um caráter tenaz. Os primeiros ensaios foram maus; três vezes saiu a pequena dos meus alambiques, sempre imperfeita. A quarta foi esforço de ciência. Quando aquela perfeição apareceu caí-lhe aos pés. O criador admirava a criatura! (ASSIS, 2008, p. 977).

É possível, nesta altura da narrativa, estabelecer um paralelo e, ao mesmo tempo, um contraponto com o Frankenstein de Mary Shelley no sentido de que Mendonça, assim como o Dr. Victor Frankenstein, fora capaz de criar uma nova vida, sem, no entanto, conferir à criatura um aspecto monstruoso e hediondo, pois havia aumentado o nível de mercúrio com a finalidade de criar uma mulher muito próxima das mulheres reais. Este fato corrobora, inclusive, o componente paródico do texto machadiano, empregado, de forma bastante irônica, com a finalidade de esvaziar o terror presente no fantástico europeu, induzindo o leitor ao riso. Apesar de seu medo inicial de que tanto pai quanto filha tivessem enlouquecido, Amaral é atraído novamente para os verdes e adoráveis olhos de Augusta: “Cousa singular! Impressionava-me aquela mulher, apesar da sua origem misteriosa e diabólica; eu sentia ao pé dela uma sensação nova, que não sei se era amor, se admiração, se fatal simpatia” (ASSIS, 2008, p.978). Torna-se também clara, a esta altura do enredo, a representação do gênero feminino enquanto um produto da criação masculina, o que encontra respaldo na citação a seguir: "não era um pai, era um autor" (ASSIS, 2008, p. 978).

Prometendo retornar na próxima noite, Amaral deixa a casa do capitão. Ao chegar a sua casa, ele começa a questionar a sequência incrível de eventos, tentando conciliar perspectivas opostas:

\footnotetext{
O que tornava a minha situação mais dolorosa e impossível de suportar era justamente a perfeita solidez da minha razão. Do conflito da minha razão com os meus sentidos resultava a tortura em que me eu achava; os meus olhos viam, a minha razão negava. Como conciliar aquela evidência com aquela incredulidade? (ASSIS, 2008, p. 979).
}

Apesar de suas apreensões iniciais, Amaral considera as pretensões da química e da alquimia, recordando-se do famoso e já citado "O homem da areia": "ocorreu-me um conto fantástico de Hoffmann em que um alquimista pretende ter alcançado o segredo de produzir criaturas humanas. A criação romântica de ontem não poderia ser a realidade de hoje?” (ASSIS, 2008, p. 979). O rapaz acaba por chegar à conclusão de que "a incredulidade de hoje é a sagração de amanhã. A verdade desconhecida não deixa de ser verdade. É verdade por si mesma, não o é pelo consenso público." (ASSIS, 2008, p. 979). Amaral considera a si mesmo como um homem de razão, e por meio da dedução e do pensamento lógico baseado em 
observações empíricas acaba por superar seus medos iniciais e aceitar uma realidade teoricamente inaceitável. Com grande resolução, e excitado por se perceber como parte de uma empreitada histórica, ele retorna à casa do capitão na manhã seguinte. Ao chegar, a própria Augusta faz uma fala que mostra que se reconhece enquanto criação masculina: "Todas as outras mulheres são filhas bastardas, eu só posso gabar-me de ser filha legítima, porque sou filha da ciência e da vontade do homem.” (ASSIS, 2008, p. 980). Mendonça, por sua vez, admite que conseguira criar a vaidade ao calibrar uma dose ainda maior de mercúrio:

Para introduzir na composição de uma criatura humana a consciência, deita-se no
alambique uma onça de mercúrio. Para fazer a vaidade dobra-se a dose do mercúrio,
porque a vaidade, segundo a minha opinião, não é mais que a irradiação da
consciência; à contração da consciência chamo eu modéstia (ASSIS, 2008, p.980).

Vale ressaltar que, após esta passagem, Augusta senta-se no piano para "tocar alguma coisa que me pareceu ser uma sonata alemã” (ASSIS, 2008, p. 981). É possível corroborar, mais uma vez, a presença da paródia do fantástico europeu no conto de Machado, retomado sarcasticamente para funcionar como ancoragem para as leitoras do jornal e para criticar, ainda que de forma sub-reptícia, a adaptação do fantástico europeu na literatura brasileira. Observase, nesta parte, o encerramento da edição de abril do Jornal das Famílias, em corte narrativo típico do romance folhetim, que objetiva criar suspense e estimular a compra e/ou leitura do próximo fascículo do periódico.

Na edição do mês seguinte, a história se reinicia com os três personagens indo ao laboratório do capitão, onde Mendonça transforma um pedaço de carvão em diamante, possibilidade esta descoberta em um livro árabe de segredos alquímicos recônditos:

Doutor, preparei hoje uma experiência em honra sua. Sabe que o diamante não é mais que o carvão de pedra cristalizado. Há tempos tentou um sábio químico reduzir o carvão de pedra a diamante, e li num artigo de revista que conseguiria apenas compor um pó de diamante, e nada mais. Eu alcancei o resto; vou mostrar-lhe um pedaço de carvão de pedra e transformá-lo em diamante. Augusta bateu palmas de contente (ASSIS, 2008, p. 981).

Durante o experimento, Amaral percebe a empolgação de Augusta e a atribui ao fato de que ela havia nascido dentro de um laboratório:

Augusta tinha efetivamente um aspecto fantástico; quando entrou no laboratório respirou largamente e com prazer, como quando se respira o ar embalsamado dos campos. Via-se que era o seu ar natal. Travei-lhe da mão, e ela com esse estouvamento próprio da castidade ignorante, puxou a minha mão para si, fechou-a entre as suas, e 
pô-las no regaço. Nesse momento passou o capitão ao pé de nós; viu-nos e sorriu à socapa (ASSIS, 2008, p. 981).

Ao saber que Mendonça aprova seu casamento com a moça, Amaral se pergunta se poderá continuar sendo um bom cristão após se casar com um produto da ciência:

A minha atenção, porém, estava toda voltada para Augusta. Não era possível ocultálo; eu já a amava; e por cúmulo de ventura era amado também. O casamento seria o desenlace natural daquela simpatia. Mas deveria eu casar-me, sem deixar de ser bom cristão? Esta ideia transtornou um pouco o meu espírito. Escrúpulos de consciência! (ASSIS, 2008, p. 982).

Antes mesmo que ele possa dar vazão aos seus conflitos, o capitão Mendonça presenteia seu futuro genro com um perfeito diamante, revelando que o casamento com Augusta depende da transformação de Amaral em um gênio como ele, Mendonça. Com um brilho diabólico em seus olhos, o capitão explica que o talento de um homem se deve à quantidade de éter encontrado em seu cérebro:

Depois de profundas e pacientes investigações, cheguei a descobrir que o talento é uma pequena quantidade de éter encerrado numa cavidade do cérebro; o gênio é o mesmo éter em porção centuplicada. Para dar gênio a um homem de talento basta inserir na referida cavidade do cérebro mais noventa e nove quantidades de éter puro. É justamente a operação que vamos fazer. (ASSIS, 2008, p. 986).

Aturdido por esta explicação, Amaral começa a querer fugir, mas é rapidamente contido e narcotizado. A operação é realizada pelo capitão Mendonça e sua filha:

De repente os olhos foram-se-me enterrando; as feições do capitão assumiram proporções descomunais e fantásticas; uma luz verde e amarela enchia todo o quarto; pouco a pouco os objetos iam perdendo as formas, e tudo em volta de mim ficou mergulhado numa penumbra crepuscular. Senti uma dor agudíssima no alto do crânio; corpo estranho penetrou até o interior do cérebro. Não sei de mais nada. Creio que desmaiei. (ASSIS, 2008, p. 987)

Quando Amaral volta a si, o laboratório está deserto. Ele vê uma cortina e escuta alguém lhe dizendo para acordar. Neste momento, descobrimos que todo o episódio iniciado após o segundo ato da peça não passava de um sonho, pois Amaral é acordado por um dos espectadores da peça: 
Acorde! quem tem sono dorme em casa, não vem ao teatro. Abri de todo os olhos; vi em frente de mim um sujeito desconhecido; eu achava-me sentado numa cadeira no teatro de S. Pedro.

- Ande, disse o sujeito, quero fechar as portas.

- Pois o espetáculo acabou?

- Há dez minutos.

- E eu dormi esse tempo todo?

- Como uma pedra.

- Que vergonha!

- Realmente, não fez grande figura; todos que estavam perto riam de o ver dormir enquanto se representava. Parece que o sono foi agitado...

— Sim, um pesadelo... Queira perdoar; vou-me embora.

E saí protestando não recorrer, em casos de arrufo, aos dramas ultra românticos: são pesados demais (ASSIS, 2008, p. 988).

Observa-se, nesta parte da narrativa, a "rasteira machadiana", o que reforça o componente paródico e nos mostra que a perturbadora história da moça de olhos verdes criada por um cientista não era verídica. Na parte a seguir, Amaral descobre ter sido, de fato, procurado no teatro por um homem chamado Mendonça:

\footnotetext{
Quando ia pôr o pé na rua, chamou-me o porteiro, e entregou-me um bilhete do capitão Mendonça. Dizia assim:

Meu caro doutor. - Entrei há pouco e vi-o dormir com tão boa vontade que achei mais prudente ir-me embora pedindo-lhe que me visite quando quiser, no que me dará muita honra.

Apesar de saber que o Mendonça da realidade não era o do sonho, desisti de o ir visitar. Berrem os praguentos, embora - tu és a rainha do mundo, ó superstição (ASSIS, 2008, p. 988).
}

Percebemos que Amaral, mesmo sabendo que tudo não passara de um sonho, desiste de visitar Mendonça por nutrir superstições a respeito da índole do capitão. Temos, portanto, um duplo movimento, sendo que o primeiro desarticula e desestabiliza a existência do fantástico, denunciando o embuste por trás dele, ao passo que o segundo aponta para a existência de um sujeito ainda muito preso às superstições emanadas a partir de narrativas perturbadoras, ainda que, intimamente, não mais confiasse no potencial de tais narrativas. Observa-se, desta maneira, que o desfecho de "O capitão Mendonça" nos leva para direções um tanto ambíguas, relacionadas às temáticas levantadas neste artigo.

\section{Considerações finais}

Como poderia uma narrativa fantástica, com uma atmosfera inquietante e assustadora, ser considerada adequada para um periódico dirigido ao público feminino? Em um primeiro momento, Machado desfaz não apenas o fantástico em si, mas o próprio "feitiço" jogado sobre suas leitoras, trazendo o mundo de volta à ordem no desfecho da narrativa. Ao tematizar o 
mercado matrimonial, materializado na possibilidade de enlace entre Amaral e Augusta, Machado tornava sua narrativa adequada ao seu público, corroendo, ao mesmo tempo, tal possibilidade ao final da narrativa com a constatação de que esta mulher era uma personagem em um sonho conturbado de um rapaz incomodado por dilemas amorosos.

No que diz respeito às configurações de gênero, a narrativa, em um primeiro momento, reforça certos papéis femininos no interior de um sistema patriarcal. Augusta, no final das contas, não é uma mulher, e sim o produto de um gênio criador masculino. Além disso, a fonte do orgulho paternal não é o amor, sendo que a filha existe para justificar seus desejos egoístas de se igualar a Deus. Toda e qualquer manifestação de individualidade da moça é resultado de manipulação alquímica masculina, ao passo que sua relação com Amaral também reforça uma mentalidade patriarcal, pois ela usa seus olhos sedutores para provocar desejos no rapaz. A "rasteira" de Machado, no entanto, nos mostra que esta mulher, conforme explicitado no parágrafo anterior, não passou de um sonho fantástico, o que nos leva a deduzir que o escritor estava questionando, em clave paródica, uma representação de gênero advinda do Romantismo europeu, tendência que invadia o mercado literário brasileiro naquela época. O desfecho de " $\mathrm{O}$ capitão Mendonça" evidencia a desconstrução da aparente ênfase em uma cultura de manipulação e objetificação da figura feminina, o que prenuncia, ainda que implicitamente, a criação de personagens fortes e independentes como Virgília em Memórias póstumas de Brás Cubas, Capitu em Dom Casmurro e Sofia em Quincas Borba, apenas para citar alguns exemplos famosos da ficção machadiana.

No que se relaciona à questão do cientificismo, Machado estaria tecendo uma crítica aos exageros da ciência, tendo em vista sua já mencionada desconfiança em relação aos avanços científicos. A crença na validade destes avanços aterroriza Amaral, que, com grande alívio, percebe que eles, na realidade, não existiam, apontando para uma crítica referente à prevalência de perspectivas estrangeiras que nenhuma relação possuíam com a realidade brasileira da época. O receio de Amaral é tão grande que ele resolve não visitar o Mendonça que lhe deixara o bilhete enquanto dormia, confirmando sua reserva acerca do cientificismo. Esta interpretação corrobora a importância da paródia para o estabelecimento da reflexividade no texto e da autorreflexividade de Machado, considerando sua lucidez em relação ao contexto em que estava inserido, presente em várias de suas crônicas publicadas nos jornais da época.

$\mathrm{O}$ conto de Machado poderia, portanto, ser interpretado como uma crítica ao desejo do sujeito do século XIX, seja ele escritor ou cientista, de controlar a realidade ao seu redor, realidade esta que incluía a ciência, o fazer literário e própria figura feminina. O modo fantástico 
aparece como estratégia utilizada pelo escritor para articular sua crítica, a qual, por aparecer de forma sub-reptícia e irônica, e por salientar a dominação de gênero em um primeiro momento, não tornou e nem tornaria o conto impublicável no Jornal das Famílias.

\section{Referências}

ASSIS, Machado de. Obra completa. Rio de Janeiro: Nova Aguilar, 2008.

BAKHTIN, Mikhail. Problemas da poética de Dostoiévski. Rio de Janeiro: Forense Universitária, 1997.

BESSIÈRE, Irene. El relato fantástico: forma mixta de caso e adivinanza. In: ROAS, David (Org). Teorías de lo Fantástico. Madrid: Arco Libros, S.L., 2001, p. 83-104.

CESERANI, Remo. O fantástico. Trad. Nilton Cezar Tridapalli. Curitiba: ed. UFPR, 2006.

CRESTANI, Jaison Luís. Machado de Assis no Jornal das famílias. São Paulo: EDUSP, 2009.

A colaboração de Machado de Assis no Jornal das famílias: subordinações e subversões. Patrimônio e memória, São Paulo, v. 1, n. 2, p. 154-183, 2006.

FURTADO, Filipe. A construção do fantástico da narrativa. Lisboa: Livros Horizonte, 1980.

GAMA-KHALIL, Marisa Martins. A literatura fantástica: gênero ou modo? Terra Roxa e outras terras, Londrina, v. 26, p. 18-31, dez. 2013.

GILBERT, Sandra; GUBAR, Susan. The Madwoman in the Attic. New Haven: Yale University Press, 1979.

HENTZ, Isabel Cristina. Filhos legítimos da ciência: os homens de ciência nos contos de Machado de Assis (1870-1884). Anais do XXVI Simpósio Nacional de História, São Paulo, 2011, p. 1-17.

HOBSBAWM, Eric. A era do capital. Trad. Luciano Costa Neto. São Paulo: Paz e Terra, 2012.

HOFFMANN, Ernst Theodor Amadeus. O homem da areia. Trad. Ary Quintella. Rio de Janeiro: Rocco, 2006.

HUTCHEON, Linda. A theory of parody: the teachings of twentieth-century art forms. New York: Routledge, 1985.

JACKSON, Rosemary. Fantasy: Literatura e Subversión. Buenos Aires: Catálogos Editora, 1986. 
JONES, Jordan; KRAUSE, James Remington. The femme fragile and femme fatale in the fantastic fiction of Machado de Assis. Abusões, Rio de Janeiro, v. 1, n. 1, p. 51-97, dez. 2015.

KRAUSE, James Remington. Enucleated Eyes: "Sem olhos" and "O capitão Mendonça" by Machado de Assis. In: DIENTE, Pablo Martínez; WISEMAN, David P. (orgs.). Border Crossings: Boundaries of Cultural Interpretation. Nashville, Tennessee: Center for Latin American Studies, Vanderbilt University, 2009, p. 51-64.

LAURETIS, Teresa de. A tecnologia do gênero. Trad. Susana Funck. In: HOLLANDA, Heloísa Buarque de. Tendências e impasses: o feminismo como crítica da cultura. Rio de Janeiro: Rocco, 1994, p. 206-242.

MAGAlHÃES JR., Raimundo. Contos esquecidos. Rio de Janeiro: Civilização Brasileira, 1956.

Contos fantásticos de Machado de Assis. Rio de Janeiro: Edições Bloch, 1976.

MASSA, Jean Michel (Org). Dispersos de Machado de Assis. Rio de Janeiro: INL, 1965.

NETO, José Raimundo Maia. O ceticismo na obra de Machado de Assis. Belo Horizonte: Annablume, 2007.

POE, Edgar Allan. Obra completa. Trad. Oscar Mendes. Rio de Janeiro: Nova Aguilar, 2001.

REGO, Enylton de Sá. O calundu e a panaceia: Machado de Assis, a sátira menipeia e a tradição luciânica. Rio de Janeiro: Forense Universitária, 1989.

RIEDEL, Dirce Cortes. A metáfora: o espelho de Machado de Assis. Rio de Janeiro: Francisco Alves, 1974.

ROAS, David. La Amenaza de lo Fantástico. In: Teorías de lo Fantástico. Madrid: Arco Libros, S. L., 2001, p. 7-44.

SCOTT, Joan. Gênero: uma categoria útil de análise histórica. Educação e realidade, Porto Alegre, v. 20, n. 2, p. 72-99, jul./dez. 1995.

SHELLEY, Mary. Frankenstein. Trad. Márcia Xavier e Brito e Carlos Primati. Rio de Janeiro: Darkside Books, 2017.

SILVA, Ricardo Gomes da. "Um esqueleto", de Machado de Assis, e outros contos parodicamente fantásticos. Dissertação de mestrado. Universidade Estadual de Londrina, Londrina, 2012.

STEILEIN, Sandra Maria. "O capitão Mendonça: um conto fantástico de Machado de Assis. Travessia, Florianópolis, n. 25, p. 32-39, 1992. 
TODOROV, Tzvetan. Introdução à literatura fantástica. Trad. Maria Clara Correa Castello. São Paulo: Perspectiva, 2004.

VOLOBUEF, Karin. E. T. A. Hoffmann e o romantismo brasileiro. Forum Deustch: Revista Brasileira de Estudos Germanísticos, Rio de Janeiro: Universidade Federal do Rio de Janeiro, n. 6, p. 103-113, 2002.

Recebido em: 25/01/2021 Aceito para publicação em: 20/04/2021 